\title{
Comparison of removal techniques in the management of buried bumper syndrome: a retrospective cohort study of 82 patients
}

다)(앙

\author{
Authors \\ Merbach $^{2}$, Arno Dormann ${ }^{5}$, Ralf Jakobs ${ }^{2}$ \\ Institutions \\ 1 Kliniken der Stadt Köln gGmbH - Medizinische Klinik/ \\ Gastroenterologie, Köln, Germany \\ 2 Klinikum Ludwigshafen - Medizinische Klinik C, \\ Ludwighafen, Germany \\ 3 Santa Casa Hospital - Gastroenterology, Porto Alegre, \\ Brazil \\ 4 Santa Casa Hospital/Porto Alegre University of Health \\ Sciences, Department of Gastroenterology, Porto \\ Alegre, Brazil \\ 5 Kliniken der Stadt Köln gGmbH - Medizinische Klinik, \\ Köln, Germany
}

Daniela Mueller-Gerbes", ${ }^{*}$, Bettina Hartmann ${ }^{*}, 2$, Julio Pereira Lima ${ }^{3}$, Michele de Lemos Bonotto ${ }^{4}$, Christoph

submitted 27.10.2016

accepted after revision 20.3.2017

Bibliography

DOI https://doi.org/10.1055/s-0043-106582 |

Endoscopy International Open 2017; 05: E603-E607

(c) Georg Thieme Verlag KG Stuttgart · New York

ISSN 2364-3722

Corresponding author

Daniela Mueller-Gerbes, Kliniken der Stadt Köln gGmbH, Krankenhaus Holweide, Medizinische Klinik,

Neufelder Str. 32, 51067 Köln

med-klinik.holweide@kliniken-koeln.de depth of the buried bumper.

\section{ABSTRACT}

Background and study aims Buried bumper syndrome is an infrequent complication of percutaneous endoscopic gastrostomy (PEG) that can result in tube dysfunction, gastric perforation, bleeding, peritonitis or death. The aim of this study was to compare the efficacy of different PEG tube removal methods in the management of buried bumper syndrome in a large retrospective cohort.

Patients and methods From 2002 to 2013, 82 cases of buried bumper syndrome were identified from the databases of two endoscopy referral centers. We evaluated the interval between gastrostomy tube placement and diagnosis of buried bumper syndrome, type of treatment, success rate and complications. Four methods were analyzed: bougie, grasp, needle-knife and minimally invasive push method using a papillotome, which were selected based on the

Results The buried bumper was cut free with a wire-guided papillotome in 35 patients (42.7\%) and with a needle-knife in 22 patients ( $26.8 \%$ ). It could be pushed into the stomach with a dilator without cutting in 10 patients (12.2\%), and was pulled into the stomach with a grasper in 12 patients (14.6\%). No adverse events (AEs) were registered in 70 cases $(85.4 \%)$. Bleeding occurred in 7 patients $(31.8 \%)$ after cutting with a needle-knife papillotome and in 1 patient $(8.3 \%)$ after grasping. No bleeding was recorded after using a standard papillotome or a bougie $(P<0.05)$. Ten of 22 patients $(45.5 \%)$ treated with the needle-knife had a serious $A E$ and 1 patient died (4.5\%).

Conclusions We recommend that incomplete buried bumpers be removed with a bougie. In cases of complete buried bumper syndrome, the bumper should be cut with a wire-guided papillotome and pushed into the stomach.

\section{Introduction}

Buried bumper syndrome (BBS) is a rare complication of percutaneous endoscopic gastrostomy (PEG) in which the internal

\footnotetext{
* Contributed equally
}

bumper migrates from the gastric lumen and becomes sites in the gastric wall (incomplete BBS) or anywhere in the tract outside the gastric lumen (complete BBS) [1 - 3]. It means that the polster ends up anywhere between the stomach mucosa and the surface of the skin. The stoma channel evolves into an abscess cavity, leaving a fistula towards the stomach lumen. This 
complication usually occurs after placing rigid or semi-rigid devices (made of polyurethane) and/or excessive traction between the internal and external bumpers [4]. The clinical symptoms of BBS are abdominal pain and secretion around the PEG insertion site, with impossibility in mobilizing and pushing the internal bumper into the stomach, feeding difficulties, peritubular leakage of instilled enteral diet or complete tube occlusion [5-7]. Diagnosis should be confirmed by endoscopy [8].

Case reports or small case series have described many different surgical and endoscopic methods for managing this complication [9-11]. For incomplete BBS (partially covered), removing the PEG by pulling internally and threading a wire through the PEG into the stomach and then pulling a new PEG down to both remove the old PEG and place a new one simultaneously is the most frequently used method (simple internal extraction). For complete BBS, cutting with a needle-knife is more often described [4]. The needle-knife can also be used in cases of partial bumper burial. Müller-Gerbes et al. [12] described a minimally invasive method where the internal bumper is cut using a papillotome and brought into the stomach from the outside under endoscopic control. After removing the papillotome, a bougie is inserted over the wire and the bumper can be pushed into the stomach and removed endoscopically with a grasper. In this study, we report the management of 82 patients with BBS, the largest case series so far.

\section{Patients and methods}

This retrospective cohort study identified all patients diagnosed with BBS at 2 referral centers in Germany (Klinikum der Stadt Ludwigshafen and Kliniken der Stadt Köln, Krankenhaus Holweide) from 2002 to 2013. The main outcome was to compare the effectiveness of different endoscopic methods for managing BBS. The secondary outcomes were to evaluate the prevalence of complications and related mortality.

During this period, all patients underwent PEG removal attempts; if removal was not possible, endoscopic procedures were performed.

Buried bumpers that were not totally covered by mucosa were removed either by pushing the PEG button into the stomach with a bougie (e. g. Savary bougie size 15F in 20F PEG tubes; $9 F$ in $15 F$ PEG tubes) after inserting a wire via the PEG from the outside or pulling it into the stomach endoscopically with a grasping device. Totally or near totally ingrown bumpers ( $\triangleright$ Fig. 1) were either removed via endoscopic needle-knife excision by cutting the overlying mucosa with a needle-knife papillotome down to the internal bumper or using a wire-guided papillotome (push method). For this method, the external tube is cut above the skin and an extra stiff wire $(0.035$ inch, $260 \mathrm{~cm})$ inserted through the shortened tube until the stomach is securely 'cannulated'. A standard papillotome should be placed over the wire ( $\mathbf{F i g . 2}$ ). Then, the papillotome is bent and drawn back until placed over the mucosa lying above the inner plate. Then, radial cutting (cutting and coagulation current, the same as for sphincterotomy) in at least 3 directions is performed by rotating the papillotome over the bumper. The tissue growing over the plate is dissected by the cutting wire.

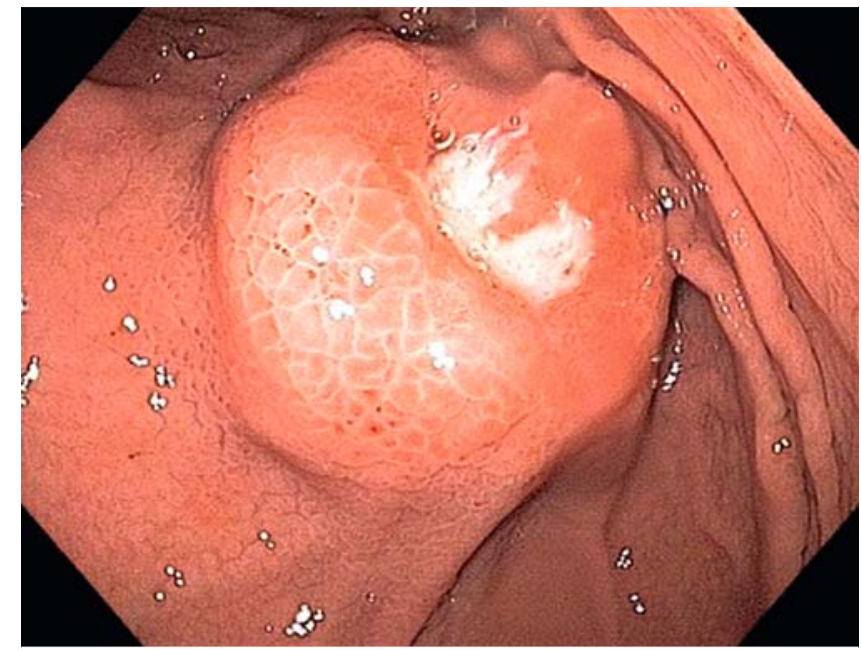

Fig. 1 Typical image of buried bumper syndrome.

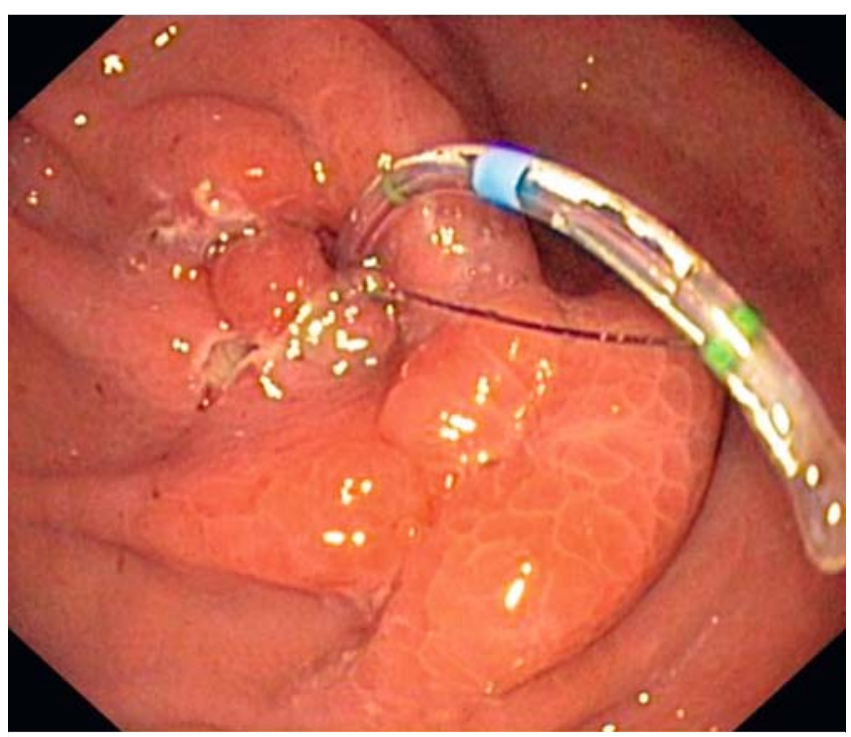

- Fig. 2 Papillotome placement from the outside.

After removing the papillotome ( $\boldsymbol{F}$ Fig.3), a bougie is inserted over the wire and the bumper can be pushed ( $\triangleright$ Fig.4) into the stomach and removed endoscopically with a snare. Thereafter, the bougie is removed, the wire remains in place and a new PEG can be placed. In all cases, a balloon system was inserted over the wire (e.g. GastroTube ${ }^{\circledR}$ ) ( Fig.5) and feeding could be started after a few hours.

\section{Statistical analysis}

All continuous variables are reported as the median (range). For categorical data, the chi-squared test or Fisher exact test was performed where appropriate. A $P$ value less than 0.05 was considered statically significant. STATA 12.1 (Stata Corp LP, College Station Texas, USA) was used for all statistical analysis. 


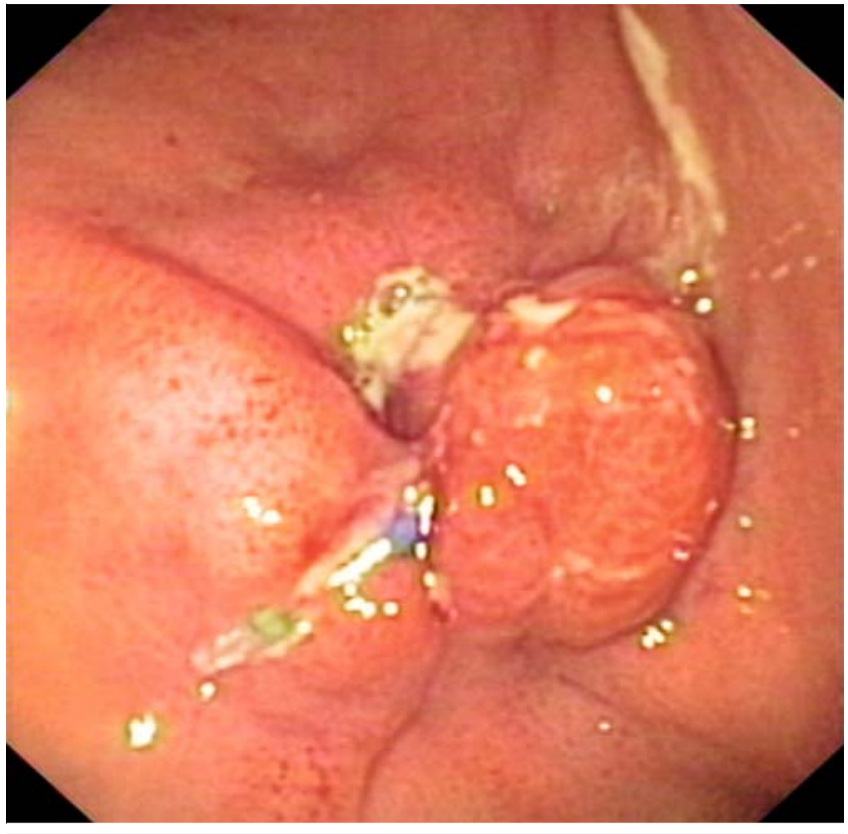

- Fig. 3 Papillotome cutting deep into the overlying mucosa.

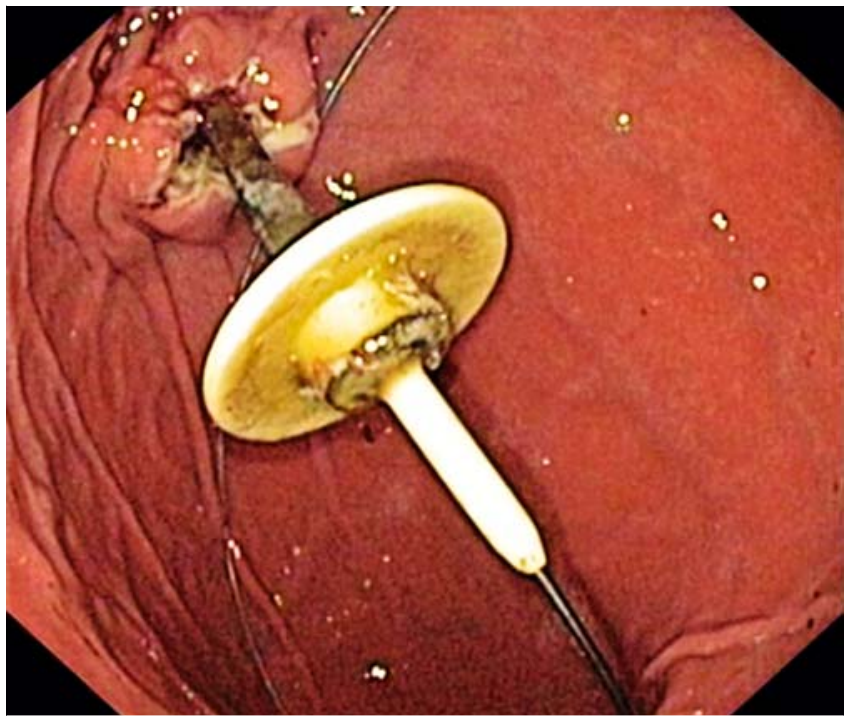

- Fig. 4 Bumper pushed into the stomach.

\section{Results}

Eighty-two patients (41 women, 41 men) with BBS were treated at the 2 centers from 2002 to 2013. Median age was 47 years (range, 15-97 years). PEG indications were enteral feeding after stroke $(n=27)$, oropharyngeal neoplasia $(n=12)$, craniocerebral injury $(n=8)$, intracerebral haemorrhage $(n=11)$, dementia $(n=8)$ and neurodegenerative disorders $(n=16)$. From 2002 to 2013 in Ludwigshafen, 1541 PEGs were inserted and 55 BBS cases were treated (prevalence of 3.6\%). From 2006 to 2013 in Cologne, 1280 patients were supplied with a PEG and 27 buried bumpers were diagnosed (prevalence of $2.1 \%$ ). Overall prevalence of BBS was $2.9 \%$. In 51 cases, the time frame from insertion to diagnosis of BBS was recorded: median, 15 months;

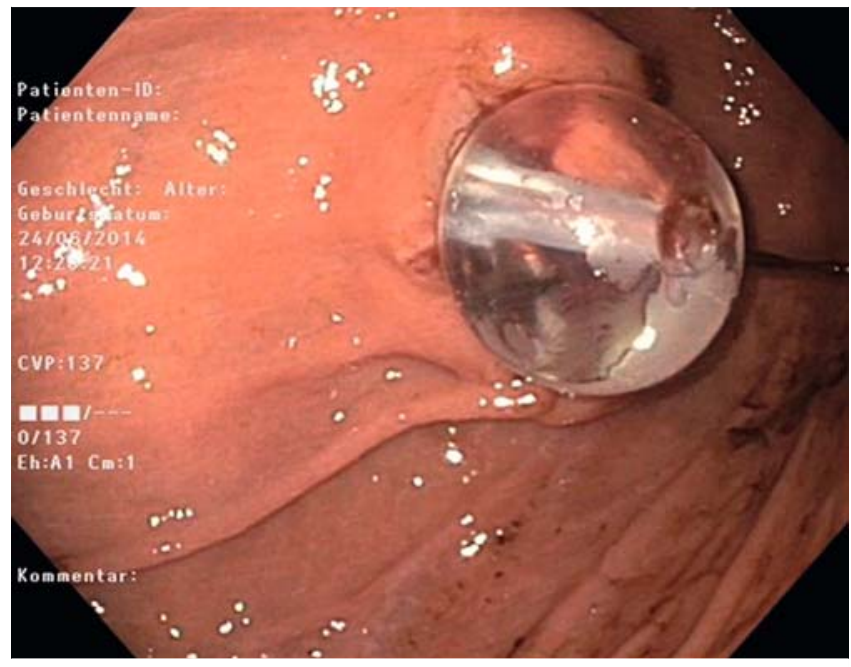

Fig. 5 Balloon system in place.

- Table1 Buried bumper removal methods.

\begin{tabular}{|l|c|c|}
\hline Method & $\mathbf{n}$ & $\%$ \\
\hline Papillotome & 35 & 42.7 \\
\hline Needle-knife & 22 & 26.8 \\
\hline Bougie & 10 & 12.2 \\
\hline Grasper & 12 & 14.6 \\
\hline Endoscopic removal & 78 & 95.1 \\
\hline Surgical removal & 4 & 4.9 \\
\hline Total & 82 & 100 \\
\hline
\end{tabular}

range, 0.5-66 months. Complete BBS was treated in 57 cases; in 35 cases $(42.7 \%)$, the buried bumper was cut free with a wire-guided papillotome and with a needle-knife in 22 cases (26.8\%). Incomplete BBS was managed in 22 patients. In 10 patients (12.2\%), the bumper could be pushed into the stomach with a dilator without cutting, and was pulled into the stomach with a grasper in 12 cases (14.6\%). In the remaining 4 cases (4.9\%), it was not possible to remove the PEG bumper endoscopically ( $\triangleright$ Table 1 ). These 4 cases date from the first recording period in Ludwigshafen, where the papillotome method had not been established yet, and were deeply grown buried bumpers that could not be removed by needle-knife. There were no adverse events (AEs) in 70 of 82 cases (85.4\%). Procedure-related complications consisted mainly of bleeding $(n=8) ; 3$ cases required blood transfusions. Bleeding occurred in 7 patients after cutting with a needle-knife and in 1 patient after pulling with a grasper. These complications were all managed endoscopically. One patient died of respiratory failure as a consequence of pneumonia 2 days after successful removal of the buried bumper with a needle-knife. Other AEs were pneumonia $(n=2)$ and bacteraemia $(n=1)$ ( $\triangleright$ Table 2$)$. Peritonitis or perforation were not recorded after the procedures. Four patients 
- Table 2 Complications after endoscopic buried bumper removal.

\begin{tabular}{|l|l|l|l|l|l|l|}
\hline Complication & $\mathbf{n}$ & $\%$ & Papillotome & Needle-knife & Bougie & Grasper \\
\hline Bleeding & 8 & 9.8 & 0 & 7 & 0 & 1 \\
\hline Pneumonia & 2 & 2.5 & 1 & 1 & 0 & 0 \\
\hline Bacteremia & 1 & 1.2 & 0 & 1 & 0 & 0 \\
\hline Non-procedure-related mortality & 1 & 1.2 & 0 & 1 & 0 \\
\hline Total & $12 / 82$ & 14.6 & $1 / 35(2.9 \%)$ & $10 / 22(45.5 \%)$ & 0 \\
\hline
\end{tabular}

had to be treated surgically after failure of endoscopic removal. In this case series, endoscopic treatment was successful in 95.1 $\%$ of cases. No episode of bleeding was recorded after excision with a wire-guided papillotome in comparison to 7 patients in the needle-knife group $(0 / 35$ versus $7 / 22, P<0.05)$. After removal of the PEG bumper with the needle-knife, $45.5 \%$ of patients (10 of 22) had a serious $A E$, and the rate of non-procedure - related mortality was $4.5 \%(n=1)$. The only complication related to wire-guided papillotome removal was a case of pneumonia $(P<0.05)$. Overall related mortality was $1.2 \%$. Peritonitis was not recorded after removal and surgical intervention after endoscopic therapy was not necessary.

\section{Discussion}

To our knowledge, this series reports the largest number of BBS cases treated by endoscopy so far. The first description of migration of the internal bumper into the gastric or abdominal wall was in 1988, [13] which was later termed "buried bumper syndrome" by Klein et al. [5]. BBS was initially regarded as an uncommon and late complication after PEG insertion. However, its prevalence is between $1.5 \%$ and $8.8 \%(2.9 \%$ in this study) $[7,14-16]$. Although usually considered a late complication, BBS also occurs as early as 21 days after PEG placement [17 - 19]. In this series, we observed a case of BBS 15 days after PEG insertion. Nevertheless, in our experience, BBS is a rather late complication of PEG, diagnosed a median 15 months after insertion.

BBS should be prevented by mobilizing the PEG tube and bumper on a regular schedule by loosening the outer fixation and pushing the tube into the stomach by at least $1 \mathrm{~cm}$ while rotating. Lack of mobilization and loosening of the bumper and continuous traction on the tube from the outside results in overgrowth of the internal bumper by the gastric mucosa and migration of the internal bumper into the gastric wall. Special education for nursing care is required.

The treatment of choice is endoscopic removal, as most patients who have undergone PEG have many comorbidities and so surgical intervention should be avoided. In cases of deep migration into the abdominal wall, surgical intervention is required (laparotomy or laparoscopy) [16, 20].

If the buried bumper is not totally covered or is impacted, it is safe to attempt to remove it with a bougie (size $15 \mathrm{~F}$ in $20 \mathrm{~F}$ PEG tubes, 9F in 15F PEG tubes) and to push it into the stom- ach. If this is not applicable, our experience suggests that it should be removed via the push method by cutting it free with a papillotome. In our study, cutting with a wire-guided papillotome was the safest approach. The method has the advantage of cutting very precisely according to the bend of the papillotome through the mucosa down to the bumper, preventing incorrect cutting and bleeding. This method provides a good internal view and the endoscopist can intervene if bleeding occurs. A second endoscopist handles the papillotome through the lumen of the shortened PEG. Bleeding occurred significantly more often after PEG bumper removal with the needle-knife method than with the papillotome method. This might be due to the use of pure cutting current with the needle-knife, while the papillotome method uses the cutting and coagulation current (blended). El et al. [21] successfully treated 5 of 8 patients with BBS with the needle-knife technique and reported no overt bleeding episodes.

In 2015, 2 new classifications were published. RichterSchrag et al. [22] recommended an endoscopic approach in stage II-IV, but stressed that conversion to the surgical method is often necessary in stage IV. Cyrany et al. [23] based their classification on clinical, endoscopic and radiographic findings and specified 5 grades, and recommended surgical therapy from stage 4 onwards.

The basic problem remains assessment of whether endoscopic therapy is possible. If the disc is visible outside the stoma, the surgical approach is clear. A computed tomographyscan or an (endoscopic) ultrasound [24] can aid evaluation of the depth of bumper migration and influence the decision. However, this was not necessary in our 82 cases. Most of our patients were stage II - IV (Richter-Schrag classification), and in 78 cases the endoscopic method was successful without radiologic evaluation. The 4 cases that were treated surgically date from the first recording period in Ludwigshafen, where the papillotome method had not been established yet and they were deeply grown buried bumpers that could not be removed by needle-knife.

These classifications can be useful for evaluating the first approach, but with the experience of 82 cases, we would always recommend the papillotome method if the buried bumper cannot be freed by pushing it with a bougie into the stomach, regardless of the stage. Only stage 5 (Cyrany classification) and stage IA-B (Richter-Schrag) need primarily surgical therapy. Endoscopic removal of PEG tubes should only be done by 
endoscopists well-trained in treating gastrointestinal bleeding. Afterwards, patients should be supplied with a balloon retaining system (e.g. GastroTube ${ }^{\circledR}$, button system) without pressure on the wound (high volume, low pressure) so nutrition can be re-established through the same stoma channel. Gluck et al. [13] suggested that the buried bumper might be left in situ and a new tube be inserted if removing the bumper appears too hazardous. Nevertheless, our data show that endoscopic removal of a buried bumper by the papillotome method is a safe alternative. Multicentre prospective studies comparing buried bumper retrieval methods should be performed to confirm our hypothesis.

\section{Conclusion}

In conclusion, we recommend that incomplete buried bumpers be removed with a bougie. In cases of complete BBS, the buried bumper should be cut with a papillotome and pushed into the stomach. In case of impossibility or failure of endoscopic removal, surgical intervention should be attempted [25].

\section{Competing interests}

None

\section{References}

[1] Bumpers HL, Collure DW, Best IM et al. Unusual complications of long-term percutaneous gastrostomy tubes. J Gastrointest Surg 2003; 7: $917-920$

[2] Hussien M, Fawzy M, Carey D. Percutaneous endoscopic gastrostomy tube migration: a rare cause of a common surgical problem. Int J Clin Pract 2001; 55: 557-559

[3] Köhler DM. [The wandering gastrostomy tube]. Ugeskr Laeger 2000; 162: $3344-3345$

[4] Blumenstein I, Shastri YM, Stein J. Gastroenteric tube feeding: Techniques, problems and solutions. World J Gastroenterol 2014; 20 : $8505-8524$

[5] Klein S, Heare BR, Soloway RD. The "buried bumper syndrome": a complication of percutaneous endoscopic gastrostomy. Am J Gastroenterol 1990; 85: $448-451$

[6] Lee T, Lin J. Clinical manifestations and management of buried bumper syndrome in patients with percutaneous endoscopic gastrostomy. Gastrointest Endosc 2008; 68: 580 - 584

[7] Mathus-Vliegen LM, Koning H. Percutaneous endoscopic gastrostomy and gastrojejunostomy: critical reappraisal of patient selection, tube function and the feasibility of nutritional support during extended follow-up. Gastrointest Endosc 1999; 50: 746-754
[8] ASGE Training Committee. Endoscopic approaches to enteral feeding and nutrition core curriculum. Gastrointest Endosc 2014; 80: 1

[9] Christiaens P, Peter B, Cuyle PJ et al. Imelda Hospital, Bonheiden, Belgium Buried bumper syndrome: single-step endoscopic management and replacement. Gastrointestinal Endosc 2014; 80: 2

[10] Curcio G, Granata A, Ligresti D et al. Buried bumper syndrome treated with Hybrid Knife endoscopic submucosal dissection. Gastrointest Endosc 2014; 80: 5

[11] Venu RP, Brown RD, Pastika B] et al. The buried bumper syndrome: a simple management approach in two patients. Gastrointest Endosc 2002; 56: $582-584$

[12] Mueller-Gerbes D, Aymaz S, Dormann AJ. Management of the buried bumper syndrome: a new minimally invasive technique - the push method. Z Gastroenterol 2009; 47: 1145-1148

[13] Gluck M, Levant J, Drennan F et al. Retraction of Sacks-Vine gastrostomy tubes into the gastric wall: report of seven cases. Gastrointest Endosc 1998; 34: 215

[14] Baskin WN. Acute complications associated with bedside placement of feeding tubes. Nutr Clin Pract 2006; 21: 40-55

[15] Finocchiaro C, Galletti R, Rovera G et al. Percutaneous endoscopic gastrostomy: a long-term follow-up. Nutrition 1997; 13: 520-523

[16] Lee TH, Lin JT. Clinical manifestations and management of buried bumper syndrome in patients with percutaneous endoscopic gastrostomy. Gastrointest Endosc 2008; 68: 580- 584

[17] Lin HS, Ibrahim HZ, Kheng JW et al. Percutaneous endoscopic gastrostomy: strategies for prevention and management of complications. Laryngoscope 2001; 111: 1847-1852

[18] Anagnostopoulos GK, Kostopoulos P, Arvanitidis DM. Buried bumper syndrome with a fatal outcome, presenting early gastrointestinal bleeding after percutaneous endoscopic gastrostomy placement. J Postgrad Med 2003; 49: 325-327

[19] Rino Y, Tokunaga M, Morinaga S et al. The buried bumper syndrome: an early complication of percutaneous endoscopic gastrostomy. Hepatogastroenterology 2002; 49: 1183-1184

[20] Boreham B, Ammori B]. Laparoscopic percutaneous endoscopic gastrostomy removal in a patient with buried bumper syndrome: a new approach. Surg Laparosc Endosc Percutan Tech 2002; 12: 356 - 358

[21] El AZ, Arvanitakis M, Ballarin A et al. Buried bumper syndrome: low incidence and safe endoscopic management. Acta Gastroenterol Belg 2011; 74: 312-316

[22] Richter-Schrag HJ, Fischer A. Buried-bumper-Syndrome A new classification and therapy algorithm. Chirurg 2015; 86: 963 - 969

[23] Cyrany J et al. Buried bumper syndrome: A complication of percutaneous endoscopic gastrostomy. World J Gastroenterol 2016; 22: $618-627$

[24] Braden B et al. Buried bumper syndrome: treatment guided by catheter probe. US Gastrointest Endosc 2003; 57: 747 - 751

[25] Nennstiel S, Schlag C, Meining A. Therapy of Buried Bumper Syndrome via NOTES - A Case Report. Z Gastroenterol 2013; 51: 744 746 